\title{
Using recycled aggregates in green roof substrates for plant diversity
}

\author{
Chloe J. Molineux ${ }^{\mathrm{a}, \mathrm{b}, *}$, Alan C. Gange ${ }^{\mathrm{a}}$, Stuart P. Connop ${ }^{\mathrm{b}}$, Darryl J. Newport ${ }^{\mathrm{b}}$ \\ a School of Biological Sciences, Royal Holloway, University of London, Egham, Surrey TW20 OEX, United Kingdom \\ ${ }^{\mathrm{b}}$ Sustainability Research Institute, University of East London, Docklands Campus, 4-6 University Way, London E16 2RD, United Kingdom
}

\section{A R T I C L E I N F O}

\section{Article history:}

Received 28 January 2015

Received in revised form 5 May 2015

Accepted 27 May 2015

Available online 15 June 2015

\section{Keywords:}

Recycled aggregates

Growing substrate

Extensive green roof

Biodiversity

Plant assemblages

\begin{abstract}
A B S T R A C T
Extensive green roofs are becoming a popular tool for restoring green infrastructure in urban areas, particularly biodiverse habitats such as post-industrial/brownfield sites. This study investigated the use of six recycled lightweight aggregates and combinations of them in green roof growing substrate, to determine their effectiveness for enhancing plant abundance and species diversity. In two separate experiments, we examined the roles of substrate type and depth on the establishment of a perennial wildflower mix over a 15-month period. We found that some of the alternative substrates are comparable to the widely used crushed red brick aggregate (predominantly found in commercial green roof growing substrate) for supporting plant establishment. For some materials such as clay pellets, there was increased plant coverage and a higher number of plant species than in any other substrate. Substrates that were produced from a blend of two or three aggregate types also supported higher plant abundance and diversity. Generally, increasing substrate depth improved plant establishment, however this effect was not consistent across substrates. We conclude that recycled materials may be viable constituents of growing substrate for green roofs and they may improve green roof resilience, through increased plant cover and diversity. The results could provide evidence to support the construction of mosaic habitat types on single roofs using various substrate blends.
\end{abstract}

(c)2015 Elsevier B.V. All rights reserved.

\section{Introduction}

Green roofs-rooftops that have been purposefully vegetated (Oberndorfer et al., 2007) either with low growing Sedum plants, wildflowers, grasses or shrubs and trees, are an emerging green technology that is becoming increasingly popular in urban environments due to the many benefits they provide. One such benefit is their potential to restore biodiversity in urban landscapes (Gedge, 2001; Grant et al., 2003; Sadler et al., 2011; Ishimatsu and Ito, 2013; Madre et al., 2014). There is an increasing body of evidence demonstrating that green roofs are able to support high biodiversity if designed appropriately (Brenneisen, 2006; Kadas, 2007; Baumann and Kasten, 2010; Tonietto et al., 2011) and increasing recognition that rich biodiversity in cities can have enormous potential to mitigate the effects of climate change through the enhancement of urban resilience and sustainability (Niemelä, 2014).

Extensive green roofs are generally designed with a substrate layer (up to $150 \mathrm{~mm}$ deep) that contains a high (up to 90\%)

\footnotetext{
* Corresponding author at: School of Biological Sciences, University of East London, Egham, Surrey TW20 0EX, United Kingdom. Tel.: +44 208223 7931; fax: +442082233327.

E-mail address: c.molineux@uel.ac.uk(C.J. Molineux).
}

percentage of aggregate and a small amount of organic material. This not only provides a low nutrient growing substrate ideal for green roof vegetation (Molineux et al., 2009; Molineux, 2010; Nagase and Dunnett, 2011) but also reduces extra roof weight. Problems can occur with either the addition of 'soil' and its attending clay fraction causing reduced water transmissivity or excessive compost/organic matter risking substrate shrinkage (Snodgrass and Snodgrass, 2006). Extensive green roofs are often vegetated using blankets, comprised of up to 12 different Sedum species and are rolled out over the substrate layer to provide an instant 'green' effect (Emilsson and Rolf, 2004). Other types of planting that are popular include wildflower and grass blankets, plug-planted systems (with either Sedum or wildflower species) and seeded systems. Biodiversity roofs tend to use both plugplants and seeds and often support local species that naturally invade the roof (Bates et al., 2013) such as Buddleia,Chenopodium spp., Trifolium spp., tree species seedlings (Salix spp.) and various grass species. These types of roofs are generally designed to mimic natural wasteland areas where bare ground can be colonized by wildflowers and grasses, with succession proceeding to scrub and finally woodland, allowing a wide range of wildlife to become established (Gibson, 1998; Angold et al., 2006). These roof level habitats often naturally retard succession due to limitations of substrate depth, water holding capacity and nutrient availability 
(Olly et al., 2011; Sadler et al., 2011). However, such stresses might also maintain a higher biodiversity level if managed effectively (Benvenuti, 2014), as dominating species can be removed (Bates et al., 2013).

The aggregate content provides the growing substrate with physical characteristics such as optimal water retention and freedraining abilities as well as good aeration, to prevent anaerobic conditions associated with compacted soils (Snodgrass and Snodgrass, 2006). Water holding capacity is of particular importance for vegetation especially during the dry summer months, and is affected by not only the substrate depth (VanWoert et al., 2005; Olly et al., 2011), but also by its type/composition (Graceson et al., 2013). Although many studies have looked at the effect of commercially available substrates on green roof hydrolytic properties (Bengtsson, 2005; Morgan et al., 2013; Wang et al., 2013; Zheng et al., 2013; Berretta et al., 2014; Volder and Dvorak, 2014), there has been little research on alternative recycled materials for use in green roof growing substrate (Molineux et al., 2009; Mickovski et al., 2013). Furthermore, fewer studies still have focused on their suitability for plant performance and diversity (Maclvor et al., 2013) and the role of different aggregates in affecting the process of succession is unknown. Successional processes on green roofs are likely to be extremely slow, mainly driven by the lack of water and nutrients (Emilsson, 2008; Bates et al., 2013) and previous experiments have concentrated upon annual plants (Nagase and Dunnett, 2013). Our aim was to determine whether different aggregates can provide satisfactory growing conditions for perennial plant species. During secondary succession, perennial herbs and grasses provide the greatest array of niches and support highest numbers of associated insects (Edwards-Jones and Brown, 1993) and maximise the biodiversity value of extensive green roofs (Madre et al., 2013). To address this question, we tested these hypotheses: (1) the type of aggregate in green roof growing substrate would affect plant establishment (abundance) and species richness; and (2) substrate depth would be important in determining plant diversity.

\section{Materials and methods}

Several recycled aggregates were chosen for this investigation and were supplied by Shire Green Roofs Substrates Ltd. (Southwater, West Sussex, UK), including: crushed red brick-typically used in extensive green roof substrate blends-and crushed yellow brick (both from defective house brick manufacture), clay pellets (containing sewage sludge and PFA), paper ash pellets (containing

Table 1

The various substrate mixes for test plot I and test plot II.

\begin{tabular}{llll}
\hline Test plot & Substrate (treatment) & $\begin{array}{l}\text { Substrate depth } \\
(\mathrm{cm})\end{array}$ & Key \\
\hline I & Clay pellets & 5.5 & $\mathrm{C}$ \\
I & Carbon8 pellets & 5.5 & 8 \\
I & Superlite mix & 5.5 & $\mathrm{~S}$ \\
I & Red brick & 5.5 & $\mathrm{R}$ \\
I & Yellow brick & 5.5 & Y \\
I & Paper ash pellets & 5.5 & P \\
I & Red brick + clay pellets + paper ash & 5.5 & RCP \\
& pellets & & \\
I & Clay pellets + paper ash pellets & 5.5 & CP \\
I & Red brick + clay pellets & 5.5 & RC \\
I & Superlite mix + paper ash pellets & 5.5 & SP \\
& & & \\
II & Paper ash pellets & 5.5 & P1 \\
II & Paper ash pellets & 8 & P2 \\
II & Yellow brick & 5.5 & Y1 \\
II & Yellow brick & 8 & Y2 \\
II & Superlite mix & 5.5 & S1 \\
II & Superlite mix & 8 & S2 \\
\hline
\end{tabular}

recycled newspaper 'ash'), Carbon8 pellets (containing limestone quarry waste and carbon dioxide) and Superlite (containing waste crushed aircrete). Full details of these aggregates are given in Molineux et al. (2009). The aggregates were used to create two green roof experimental test sites and the combinations of aggregates used are listed in Table 1 . For all treatments, $75 \% / \mathrm{v}$ aggregates were combined with $25 \% / v$ organics (50:50 blend of PAS100 compost and loam) to produce novel substrate blends. Where more than one aggregate was used, equal ratios of them were blended, e.g. $33.3 \%$ red brick, $33.3 \%$ clay pellets and $33.3 \%$ paper ash pellets then $75 \%$ of this mixed material combined with the same $25 \% / \mathrm{v}$ organics. The amount of organics added to aggregates in this study was justified based on FLL Guidelines of $\leq 65 \mathrm{~g} / \mathrm{l}$ (FLL, 2008), suggestions by Beattie and Berghage (2004) of between $10 \%$ and $25 \%$ organic matter and previous investigations by Molineux et al. (2009).

\subsection{Green roof experimental site}

An experimental modular green roof was set up in May 2008 on the roof of the Bourne Laboratory (5 stories high) at Royal Holloway, University of London, Egham (Fig. 1). A series of prefabricated gravel trays $(52 \mathrm{~cm} \times 42 \mathrm{~cm} \times 8 \mathrm{~cm})$ were drilled with holes to allow for water drainage and lined with a filter membrane (ZinCo SF, ZinCo, Germany) to prevent particulate matter from washing into the drainage system. The experimental site was divided into two test plots (I and II) in order to investigate two variables: aggregate type and substrate depth respectively.

In test plot I, 50 trays contained 10 different substrate types; six was single substrates and four was of various combinations (Table 1). They were arranged in a randomized block design whereby each of the 10 substrates (treatments) appeared once per row and rows were replicated randomly, five times. Each tray was filled to $5.5 \mathrm{~cm}$ deep and seeded with $2.5 \mathrm{~g}$ of seed mix, equating to $10 \mathrm{~g} \mathrm{~m}^{-2}$ (Table 2). The amount of organics and seeds applied to each tray was kept constant, as was the depth of the substrates to ensure that the only variable in the experimental design was the type of aggregate. Watering came from rainfall alone (even throughout dry summer months) for a true representative, lowmaintenance and extensive green roof situation. Because of this a high sowing rate of seeds was used. Previous research has found that if seeds are not watered initially for establishment (Monterusso et al., 2005), then a higher rate of sowing is required for increased individual numbers (Nagase and Dunnett, 2013).

In test plot II, there were 30 trays containing three substrates at two different depths (Table 1), $5.5 \mathrm{~cm}$ and $8 \mathrm{~cm}$. Here, each of the six treatments was also replicated five times and seeded with $2.5 \mathrm{~g}$ per tray. The purpose of this test plot was to determine if substrate depth altered plant species richness and abundance within the same substrate type. Due to weight restrictions on the roof, only three aggregates could be tested, therefore substrates that had not performed as well in preliminary greenhouse trials (Molineux, 2010) were selected, to see if increasing depth could improve their performance.

\subsection{Plant performance}

In test plot I, plant surveys were conducted at six (November 2008), nine (February 2009) and fifteen (August 2009) months post-construction. As all plant species in seed mix were perennials, this allowed monitoring of establishment at end of year one and then overwinter and the summer of year two. On each date, the number of each plant species in each tray was recorded. Species identification followed Fitter et al. (1996). The survey of test plot II was conducted once, after 15 months. 
Test Plot I

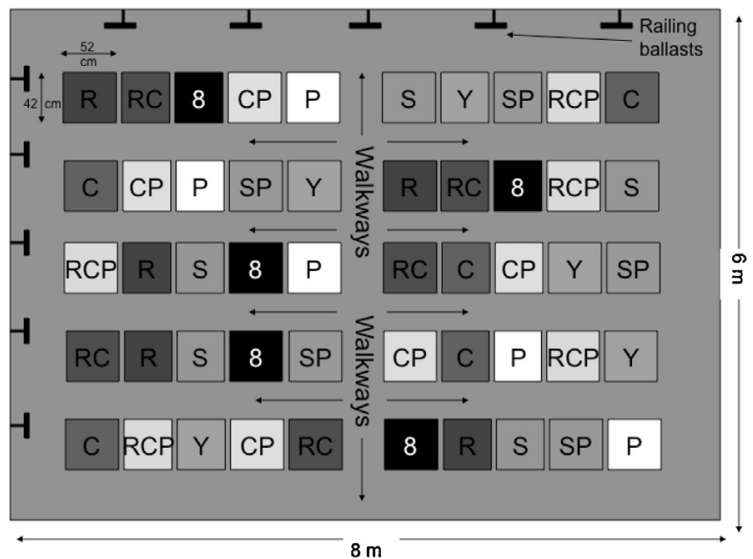

Test Plot II

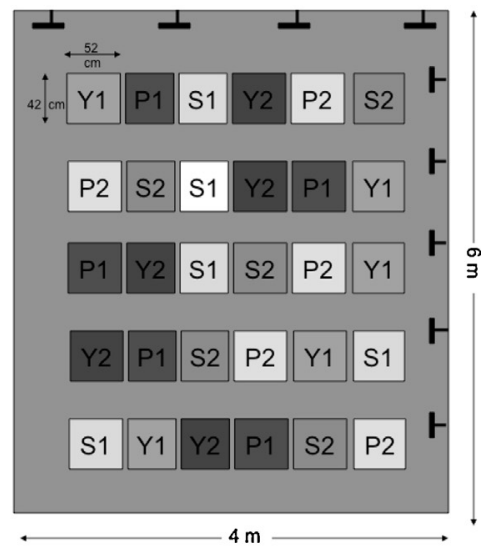

Fig. 1. Bourne roof test plots I and II, $80(52 \mathrm{~cm} \times 42 \mathrm{~cm})$ trays arranged in a randomized block design.

Where $\mathrm{C}=$ clay pellets, $8=$ Carbon 8 pellets, $\mathrm{S}=$ Superlite, $\mathrm{R}=$ red brick, $\mathrm{Y}=$ yellow brick and $\mathrm{P}=$ paper ash pellets.

Table 2

The 15 wildflower plant species and 1 grass species in the seed mix sown in the test plots.

\begin{tabular}{llll}
\hline Family & Genus & Species & Common name \\
\hline Boraginaceae & Echium & Vulgare & Viper's-bugloss \\
Caprifoliaceae & Knautia & arvensis & Field Scabious \\
Compositae & Centaurea & nigra & Common Knapweed \\
Compositae & Leucanthemum & vulgare & Oxeye Daisy \\
Compositae & Leontodon & hispidus & Rough Hawkbit \\
Lamiaceae & Origanum & vulgare & Wild Marjoram \\
Plantaginaceae & Plantago & media & Hoary Plantain \\
Rubiaceae & Galium & Verum & Lady's Bedstraw \\
Poaceae & Bromus & erectus & Upright Brome grass \\
Hypericaceae & Hypericum & Perforatum & Perforate St John's-wort \\
Leguminosae & Anthyllis & Vulneraria & Kidney Vetch \\
Leguminosae & Lotus & corniculatus Bird & Bird's-foot-trefoil \\
Leguminosae & Trifolium & Pratense & Red Clover \\
Malvaceae & Malva & Moschata & Musk-mallow \\
Ranunculaceae & Ranunculus & Acris & Meadow Buttercup \\
Resedaceae & Reseda & Lutea & Wild Mignonette \\
\hline & & &
\end{tabular}

\subsection{Statistical analysis}

Diversity was calculated using the Shannon-Weiner index. Following checking of data sets for normality and homogeneity of variances, repeated measures analysis of variance (ANOVA) was used to examine differences in numbers of plants established, species richness and diversity, employing time and substrate type as the main effects. Means were separated with a Tukey's HSD post hoc test (Fowler et al., 1998). ANOVA was also used to examine the effect of substrate depth on abundance and diversity. These analyses were conducted using the statistical package UNISTAT ${ }^{\mathbb{R}}$.

We also employed non-metric multidimensional scaling analysis to examine differences in the plant assemblage composition after 15 months across the different aggregates, using the CAP5 package (Pisces Conservation Ltd., Lymington, UK). ANOSIM was used to examine pairwise assemblage differences.

\section{Results}

\subsection{Aggregate type: assemblage analysis}

In the first 6 months post construction of test plot I, many seedlings emerged from all trays (mean of $18.5 \pm 1.7$ per tray across all treatments). However over the first year many did not survive, leaving most trays looking sparse and after 15 months there was a mean of $12.5 \pm 1.1$ per tray (of all treatments). Fig. 2 shows the changes in plant numbers in the different substrate blends over the course of the 15 months study. Initial establishment seemed to be slower in the clay pellets, Carbon 8 pellets and Superlite mix (Fig. 2a), but once established, plant abundance tended to remain stable. In the other single aggregates (red brick, yellow brick and paper ash pellets, Fig. 2b) and the blended mixtures (Fig. 2c), initial establishment was good, but plant persistence was poor, leading to a decrease in numbers over time. Overall the change in plant abundance was significant over time $\left(F_{2,108}=9.7, P<0.01\right)$, but more importantly, and there was a considerable difference in plant abundance between the substrates $\left(F_{9,108}=15.4, P<0.001\right)$. This is summarised in Fig. 3a, where it can be seen that Superlite, yellow brick and paper ash pellets were not as effective for supporting plant abundance as the other aggregate types. Meanwhile, the largest numbers of plants established were found in those substrates containing red brick and/or clay pellets.

Out of the 16 species that were seeded (Table 2), 10 (Echium vulgare, Leontodon hispidus, Origanum vulgare, Galium verum, Bromus erectus, Anthyllis vuleraria, Lotus corniculatus, Trifolium pratense, Malva moschata and Ranunculus acris) established successfully in at least one of the trays. Once germination had occurred, there was no overall change in plant species richness over time, but a dramatic difference between the aggregates $\left(F_{9,108}=18.6, P<0.001\right)$. Fig. $4 \mathrm{a}$ and $\mathrm{b}$ shows species richness from the single aggregate blends and Fig. $4 \mathrm{c}$ shows the number of species found in the blended substrates. Species richness in the different aggregates did not follow an identical trend to plant abundance. The number of plant species was higher in the clay pellets and the mixes of red brick/clay pellets/paper ash pellets and red brick/clay pellets treatments closely followed by the crushed red brick and the clay/paper ash pellet mix. The carbon8 pellets, Superlite mix, paper ash pellets and the yellow brick substrate were the least species rich substrates overall (Fig. 3b). Diversity increased over time $\left(F_{2,12}=5.4, P<0.05\right)$ and differed greatly between the aggregates $\left(F_{9,108}=14.2, P<0.001\right)$. This followed a similar pattern to species richness (so data not shown), in that Superlite, paper ash pellets and yellow brick were the least diverse, while aggregates with red brick and/or clay pellets produced the most diverse assemblages. The assemblage pattern was confirmed by the ordination analysis (Fig. 5). A significant separation in the assemblages was found $(r=0.224, P<0.001)$, with yellow brick and 
(a)

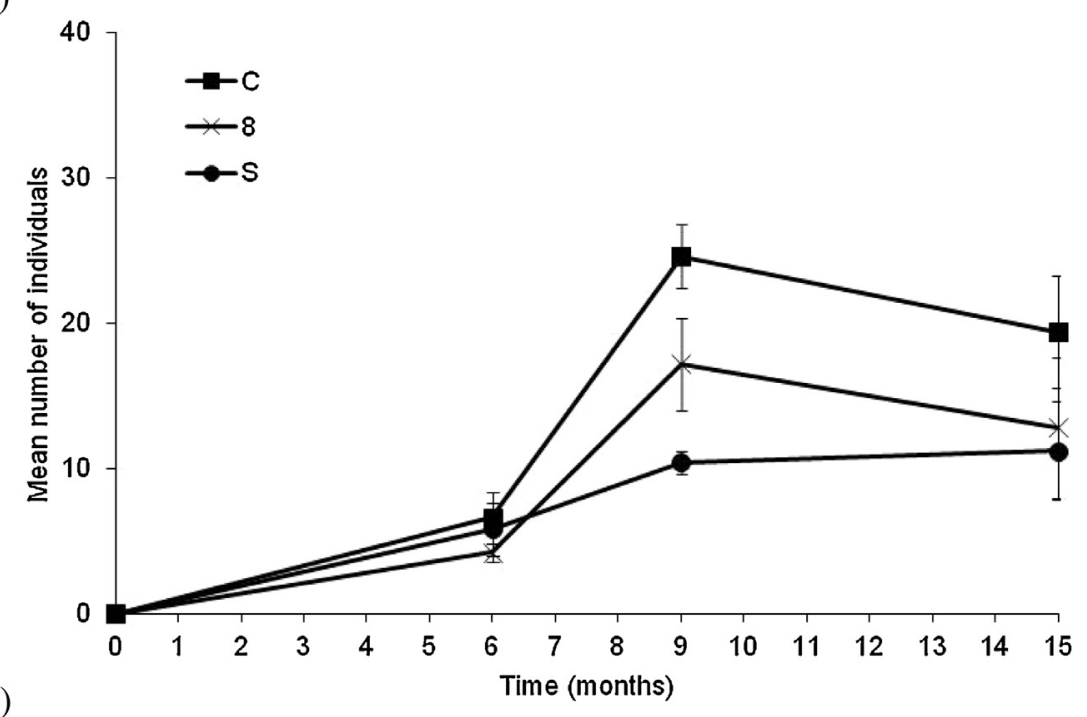

(b)

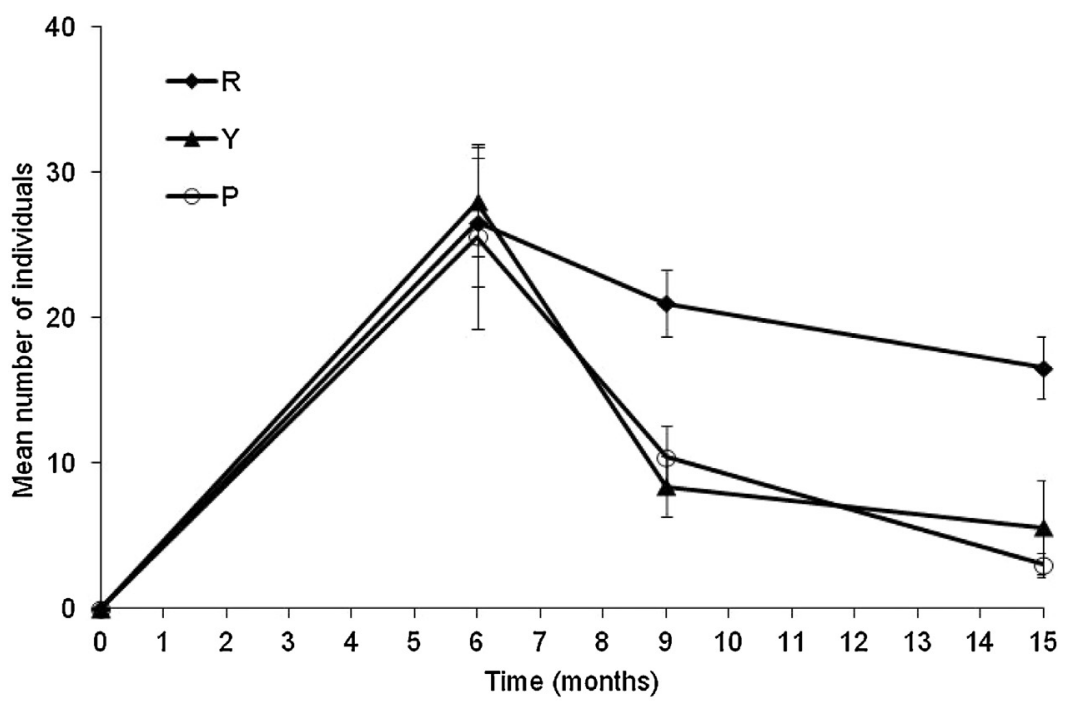

(c)

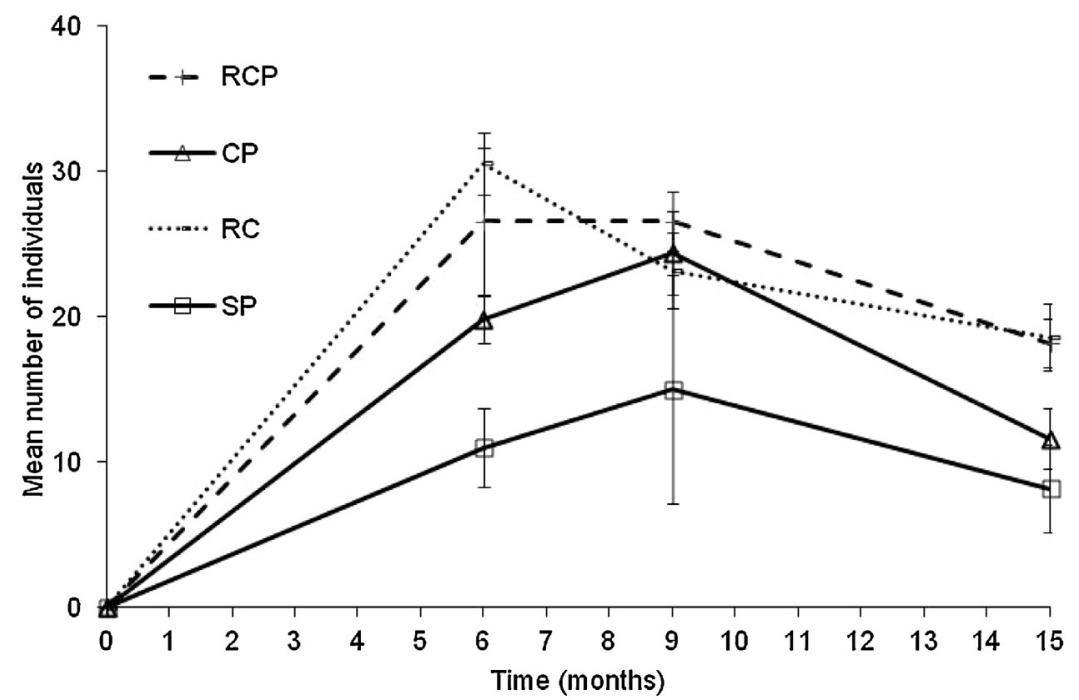

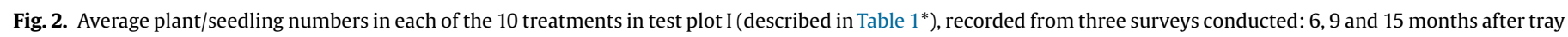

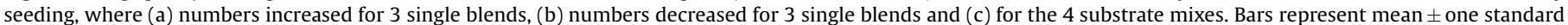
error. ${ }^{*} \mathrm{C}=$ clay pellets, $8=$ Carbon 8 pellets, $\mathrm{S}=$ Superlite, $\mathrm{R}=$ red brick, $\mathrm{Y}=$ yellow brick and $\mathrm{P}=$ paper ash pellets. 
(a)

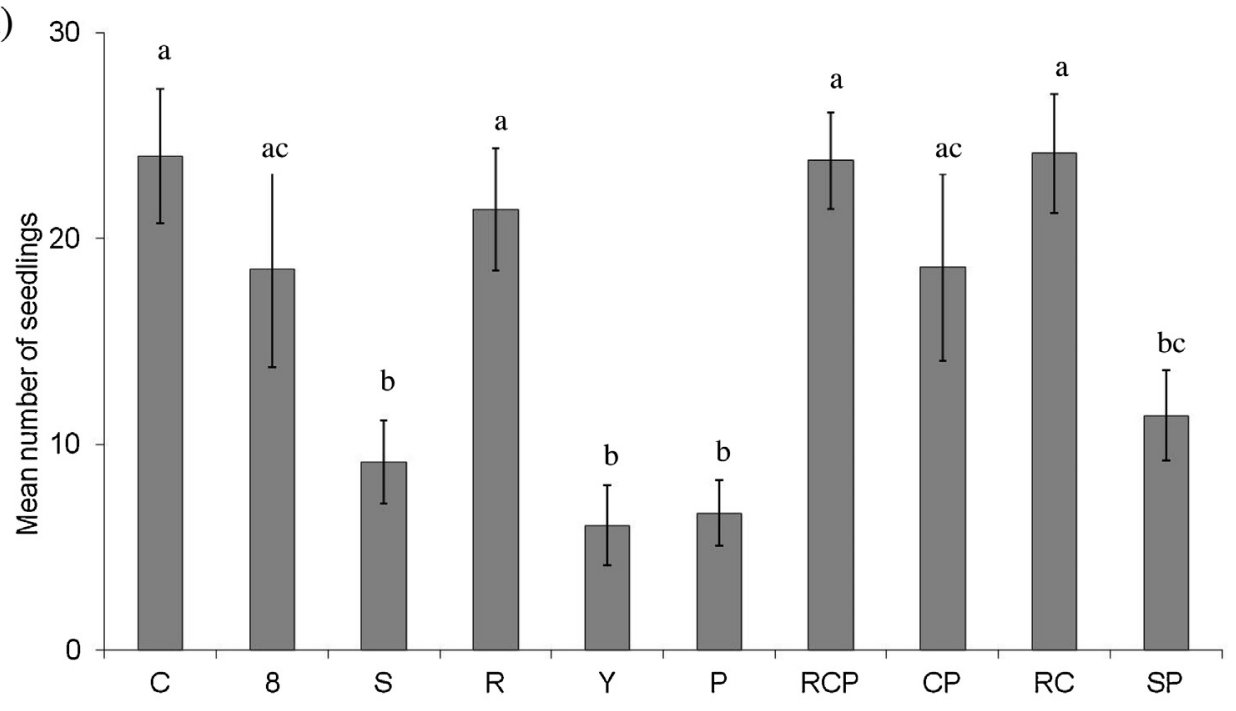

(b)

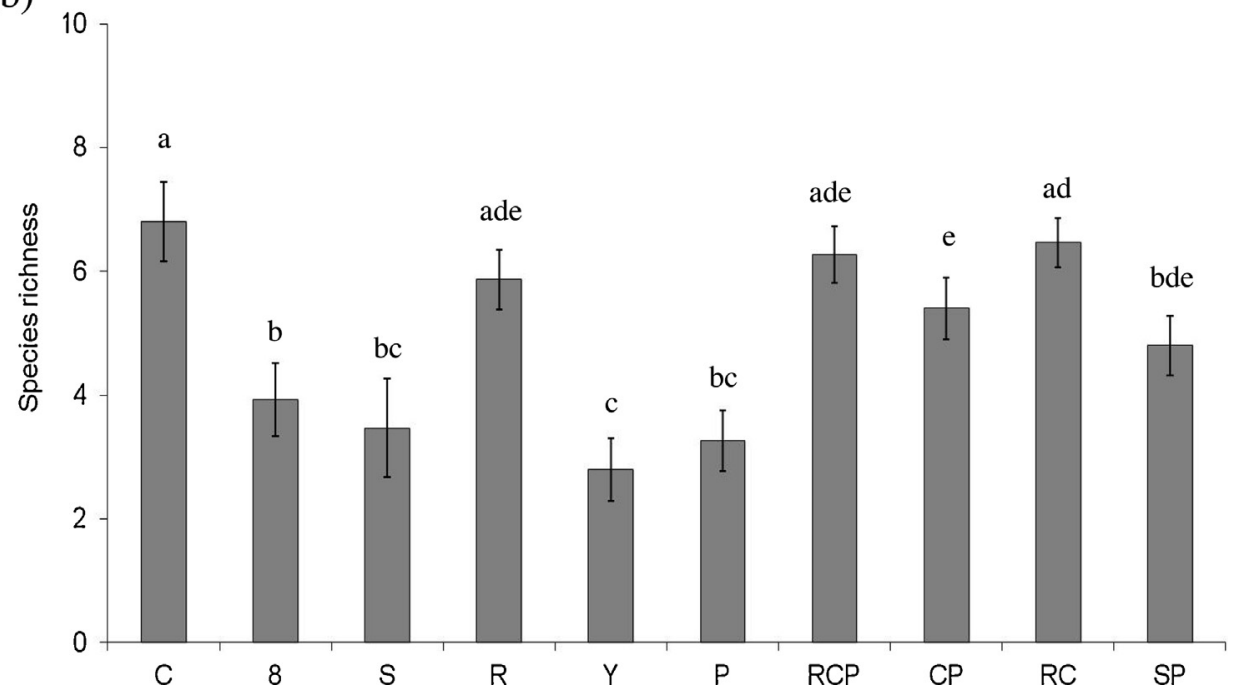

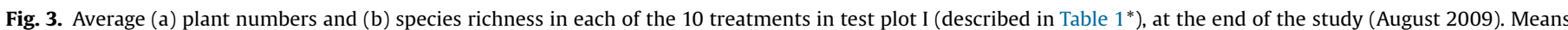

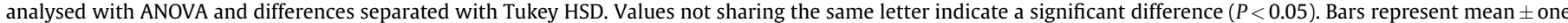
standard error. ${ }^{*} \mathrm{C}=$ clay pellets, $8=$ Carbon 8 pellets, $\mathrm{S}=$ Superlite, $\mathrm{R}=$ red brick, $\mathrm{Y}=$ yellow brick and $\mathrm{P}=$ paper ash pellets.

paper ash supporting assemblages that were very different from all other substrates.

\subsection{Aggregate type: plant species analysis}

At the end of the study in August 2010, E. vulgare was the most abundant plant species and seemed suited to most substrates and blends. Mean numbers of plants varied slightly between substrates $\left(F_{9,40}=2.2, P<0.05\right)$, with fewer plants established in paper ash pellets and yellow brick. Other plant species followed similar patterns of abundance, though no statistical differences were found between substrates, with the exception of L. hispidus, where numbers were extremely low in the Superlite, paper ash pellets and yellow brick substrates.

\subsection{Aggregate depth}

Overall, both plant number $\left(F_{1,23}=11.92, P<0.01\right)$ and species richness $\left(F_{1,23}=7.88, P<0.01\right)$ were higher in $8 \mathrm{~cm}$ deep substrates than $5.5 \mathrm{~cm}$ (Fig. 6). However, this pattern was only seen in substrates that contained paper ash or Superlite, and was not true for yellow brick. For species richness, this resulted in a significant interaction term between aggregate type and depth $\left(F_{2,23}=5.16\right.$, $P<0.05)$ implying that the effectiveness of a particular aggregate type very much depends on its depth.

\section{Discussion}

This study has shown that it is possible on a green roof to establish an assemblage composed of herbaceous perennial plants in varying admixtures of recycled inorganic substrates. Certain plant species such as E. vulgare, $L$. corniculatus, $T$ pratense and $B$. erectus established well, but their persistence also differed between substrates.

In all substrates, there was good seedling germination, but establishment in clay pellets, Carbon 8 and Superlite seemed to be particularly slow. Once established, however clay pellets appeared to provide a good medium for plant growth and resulted in one of 
(a)

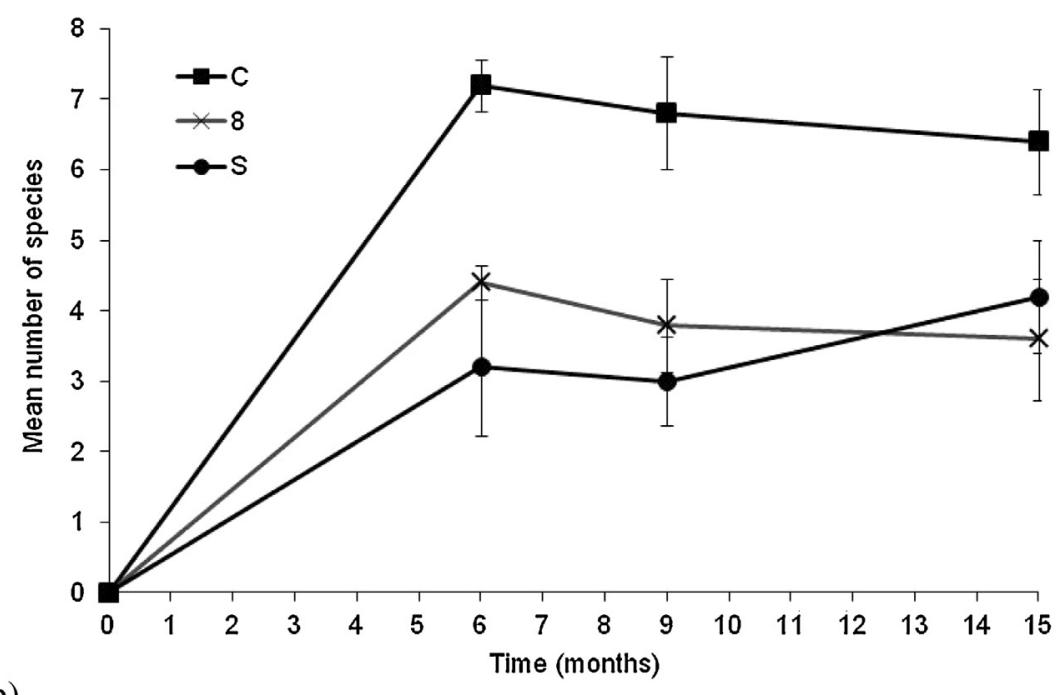

(b)

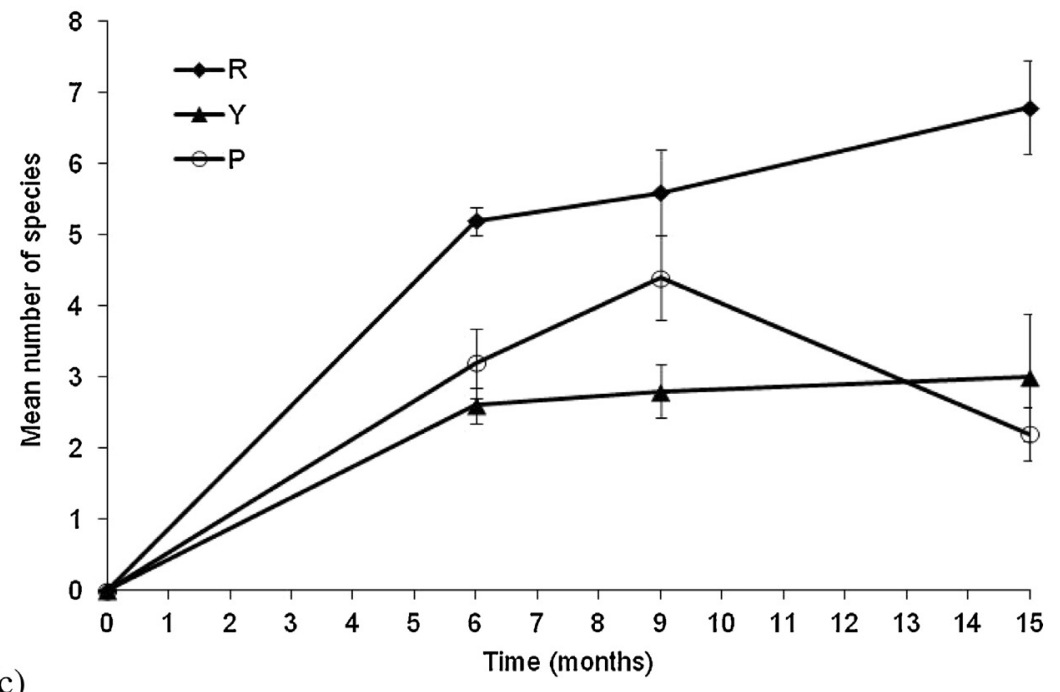

(c)

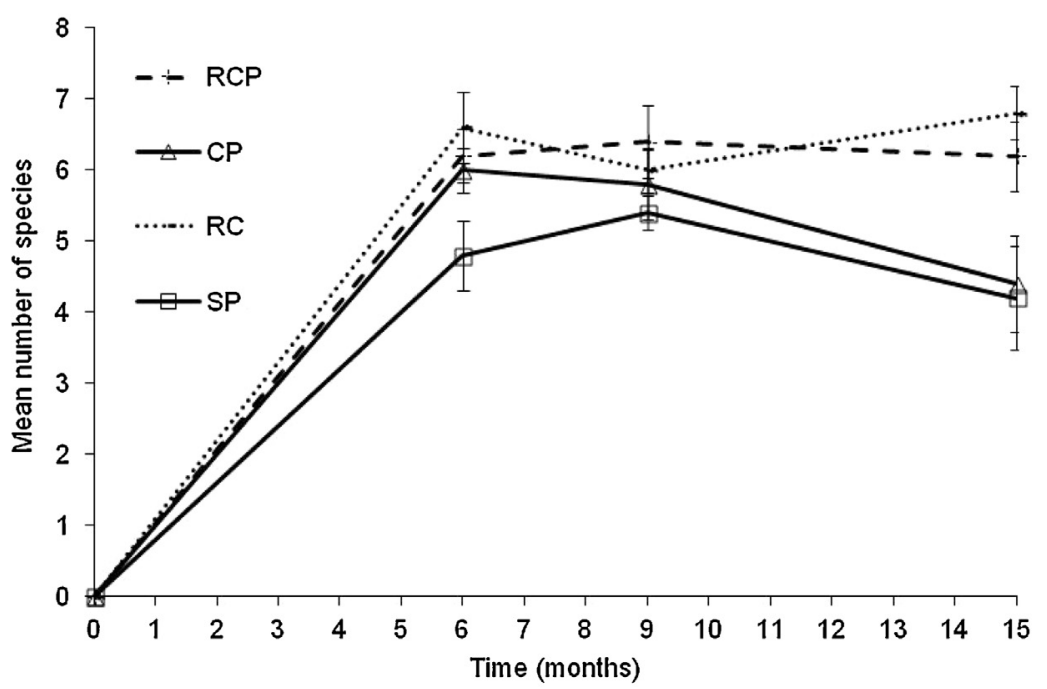

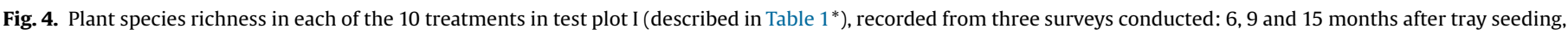

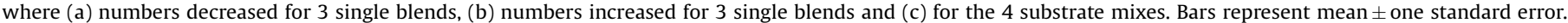
${ }^{*} \mathrm{C}=$ clay pellets, $8=$ Carbon 8 pellets, $\mathrm{S}=$ Superlite, $\mathrm{R}=$ red brick, $\mathrm{Y}=$ yellow brick and $\mathrm{P}=$ paper ash pellets. 


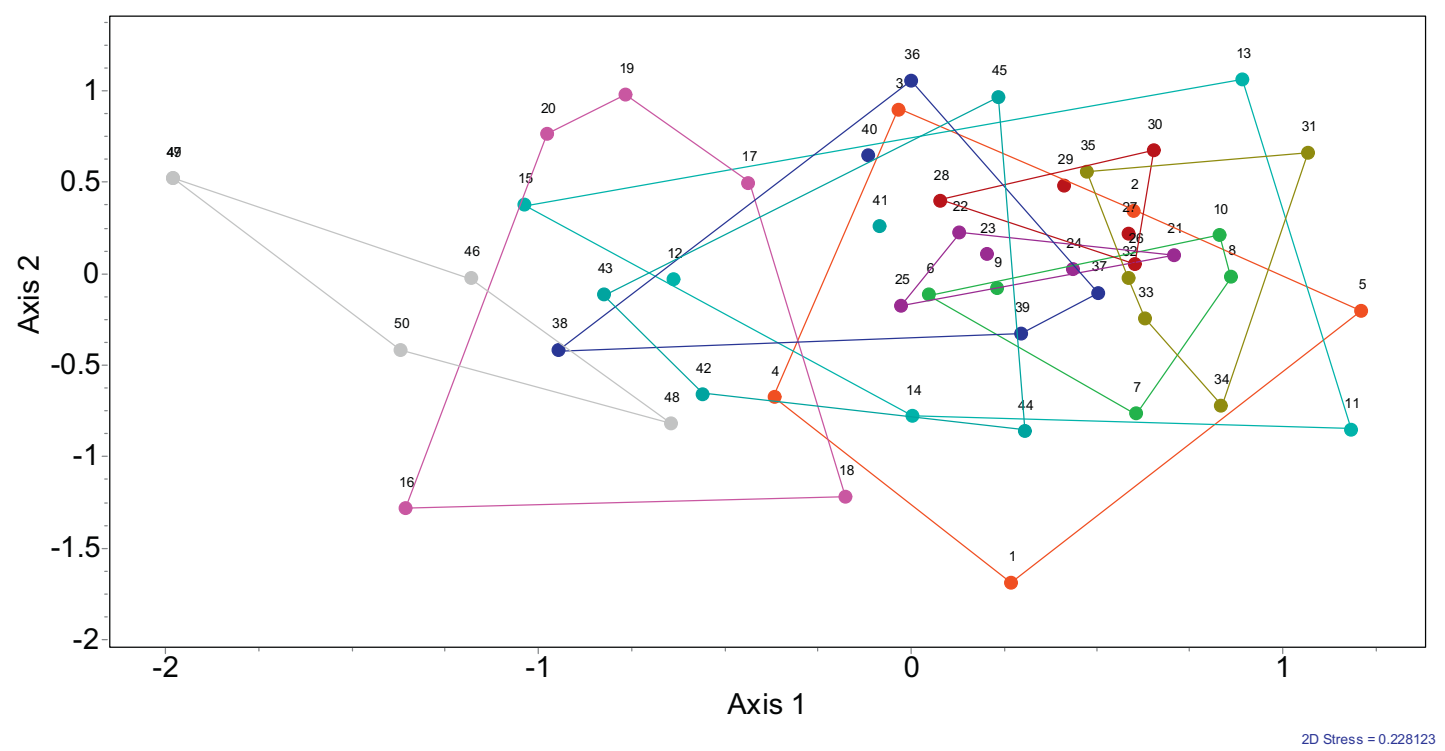

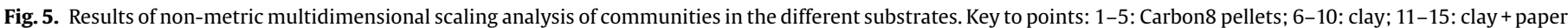

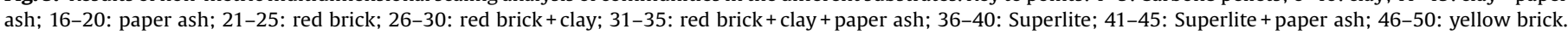

the most diverse communities. On average, the rate of emergence was around $70-75$ plants $\mathrm{m}^{-2}$, even with a higher sowing rate (approximately $10 \mathrm{~g} \mathrm{~m}^{-2}$ ) compared to other studies which recorded between 90-300 plants $\mathrm{m}^{-2}$ (Benvenuti, 2014). Indeed Benvenuti (2014) suggests that this may be due to the

(a)

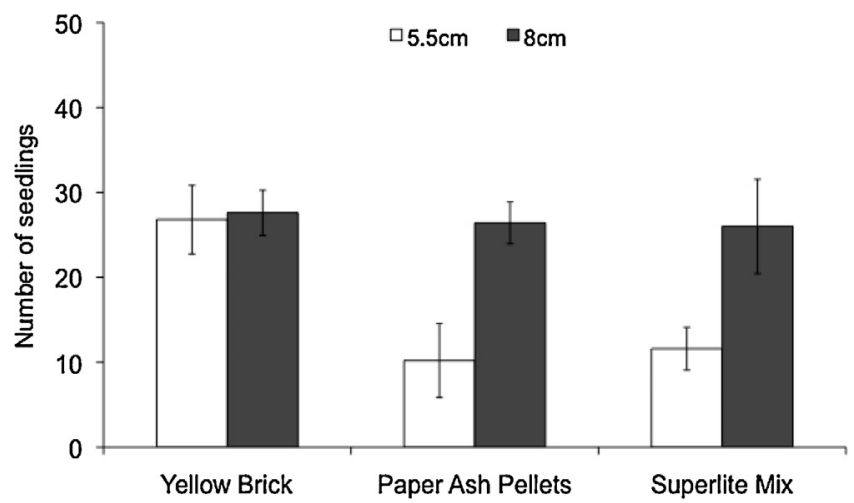

(b)

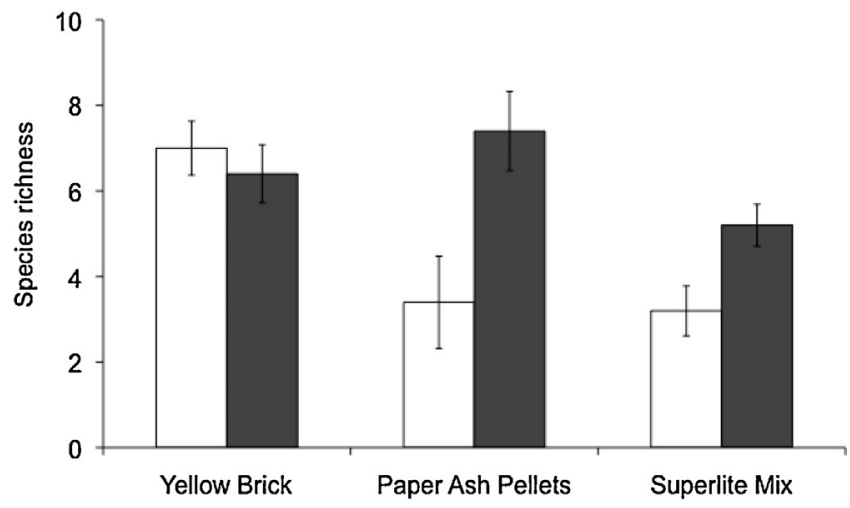

Fig. 6. (a) Plant/seedling numbers and (b) species richness, in each of the six treatments in test plot II; including 3 substrates at 2 depths. Bars represent mean \pm one standard error. characteristic dormancy of wild flower seeds and the faster growth of flora due to warmer conditions at roof level. Findings from this investigation seemed to suggest that for the first couple of years on a new green roof there is an initial surge of plant life, which becomes less over time as competition between larger plants arises (Nagase and Dunnett, 2013), nutrients are reduced and certain individuals struggle to survive in the harsh conditions. Once this phase has passed, seeds that were not in the original mix (such as Chenopodium album, as found in this study) were able to colonise the substrates (Madre et al., 2014). However some invaders may be of the same species-possibly with a more hardy advantage over the commercially bought seeds (Vander Mijnsbrugge et al., 2010)-resulting in reduced individual plant numbers over time but a constant number of species maintained within the substrates. It should be noted that this was a short-term study and that the number of species may be reduced in subsequent years, as found by Dunnett and Kingsbury et al. (2008), Nagase and Dunnett (2010) and Benvenuti (2014) as some species become more dominant.

One third of the species in the seed mix were never observed in the experimental units. This may have been due to the time of seeding and perhaps the need for certain species to undergo scarification or more favourable environmental conditions before germination (Hull, 1974). It may also have been due to the harsh conditions on the green roof, such as the thin substrate layers (Madre et al., 2014), severe drought stress during hot, dry months (Bousselot et al., 2011) and the limited nutrients available (Emilsson et al., 2007). The biological, physical and chemical properties of the various growing substrate may also have affected plant germination and survival (Molineux et al., 2009, 2014).

The substrates containing clay pellets were overall the most effective for plant diversity and supported the most individuals at the time of the 9 months survey. This is likely due to the good water holding capacity of these pellets and that in their 'raw' state, $\mathrm{pH}$ is not high, and can be reduced to neutral with addition of organic matter (Molineux et al., 2009). For similar reasons, red brick was also a good aggregate to use in the blends for several plant species, especially $E$. vulgare, $L$. corniculatus and $T$. pratense. Not only did these substrates support higher diversity, they also tended to provide a more even establishment of plants, suggesting that they 
would be of greater value for use in green roof designs. If there is less variation from roof to roof, then the process of installing species-rich green roofs in different locations will become more predictable. Substrates with the combination of these two aggregates (RC) supported the highest numbers of both species and individuals by the end of the study. Meanwhile, paper ash pellets were particularly poor at supporting plant establishment and growth, most probably due to their limited water holding capacity and that organic matter addition has less of an effect on reducing their high pH (Molineux et al., 2009). Only when these pellets were mixed with clay and red brick was the performance acceptable. This suggests that over time substrates are more successful if they comprise of a blend of different materials. The differences in physical characteristics of these aggregates probably contribute to this success on both a particle and chemical level, indeed previous research by Molineux et al., 2009 and more recently Graceson et al., 2013 show that the combination of aggregates with organics changes the original properties of the materials making some substrates more effective at storing water and releasing it to plants when needed than others. Thus, there are often interactions between the substrate components that are hard to predict or calculate from just laboratory-based experiments; this highlights the importance of carrying out rooftop level research.

The ordination analysis showed that the paper ash pellets and yellow brick supported assemblages that were very different to the other substrates, specifically being impoverished in numbers and diversity. This is likely due to the physical and chemical properties, such as water holding capacity and $\mathrm{pH}$ of these substrates (Molineux et al., 2009). Other substrates produced assemblages that was persistent over two summer growing seasons, an important factor in creating sustainable communities. It has long been known that communities composed of perennial plants support greater numbers of insects and associated organisms than do the ruderal communities characteristic of early succession, dominated by annual plants (Southwood et al., 1986; Brown et al., 1987). It is thus desirable to attempt to establish such perennial assemblages on green roofs, for the purposes of biodiversity enhancement in urban environments. This study has shown that establishment of the community is certainly feasible. The fact that the highest levels of associated faunal diversity can be achieved with the creation of mosaic habitat is a concept that could be achieved with areas of varying substrate types and depths on green roofs (Gedge et al., 2012). It is important now to conduct experiments that involve the most promising mixtures of aggregates and to monitor the establishment of the associated insect communities.

The establishment and persistence differences between the same substrates at different depths in test plot II showed that the paper ash pellets and Superlite mix were significantly improved. For example, increasing depths from $5.5 \mathrm{~cm}$ to $8 \mathrm{~cm}$, vastly improved both abundance and species richness. This indicates that it is not some chemical property such as $\mathrm{pH}$ that resulted in poor performance, instead it is more likely to be water holding capacity, which would be increased by depth (Durhman et al., 2007). These results also support early work by Brenneisen (2006) and Kadas (2007) and more recent research by Köhler and Poll (2010) and Madre et al. (2014), where they all show depth to be the most important factor for plant species richness. However in this study, the one exception was yellow brick, which did not improve species richness and, in fact, showed a small though statistically insignificant decrease in species numbers when the depth was increased. It is not known what property of yellow brick made it so unsupportive of plants in plot I and plot II, but it may be a physical attribute rather than a chemical one. Graceson et al. (2013) suggest that increasing substrate depth may not increase water retention capabilities of certain substrate types because of the intra-particle and inter-particle pore spaces available for water holding. As a general rule, increased depth would be beneficial for plant growth in most cases but substrate type also plays a vital role in green roof design. Importantly adding $2.5 \mathrm{~cm}$ to the depth of a roof will increase its weight and would not be structurally desirable in some instances.

\section{Conclusions}

This study has shown that the establishment of perennial plants on green roofs is possible and that these plants can survive over two growing seasons. The most effective substrate for plant biodiversity varied over time, but admixes (blends of two or more different aggregates) performed particularly well in terms of both coverage and plant species richness. In particular, red brick, clay pellets and a combination of the two offer very promising substrates for the maximization of plant diversity and a more even establishment of plants. For poorer performing substrates, coverage and species richness is enhanced (in most cases) with greater substrate depth, and depth alone can vastly improve the performance of a particular aggregate that may not be very successful if used at shallow depths of $5.5 \mathrm{~cm}$. It would be interesting to see if this trend changes in subsequent years, particularly with regards to different weather patterns. Therefore the hope for future research is long-term monitoring of extensive green roofs using a range of novel recycled substrates, to determine just how resilient these urban habitats could be. Furthermore, their abilities to support communities of associated insects and birds need to be tested over extended periods of time.

\section{Acknowledgements}

We are grateful to the Natural Environment Research Council (NERC) for funding this research, and to the EU FP7 project Transitioning towards Urban Resilience and Sustainability (TURAS) for post-analysis funding. Thanks also go to Shire Green Roof Substrates Ltd. for supplying the materials used and to the two anonymous reviewers for their helpful comments.

\section{References}

Angold, P.G., Sadler, J.P., Hill, M.O., Pullin, A., Rushton, S., Austin, K., Small, E., Wood, B., Wadsworth, R., Sanderson, R., Thompson, K., 2006. Biodiversity in urban habitat patches. Sci. Total Environ. 360, 196-204.

Bates, A.J., Sadler, J.P., Mackay, R., 2013. Vegetation development over four years on two green roofs in the UK. Urban For. Urban Greening 12, 98-108.

Baumann, N., Kasten, F., 2010. Green roofs - urban habitats for ground-nesting birds and plants. In: Muller, N., Werner, P., Kelcy, J.G. (Eds.), Urban Biodiversity and Design. John Wiley and Sons, Chichester, pp. 348-362.

Beattie, D., Berghage, R., 2004. Green roof media characteristics: the basics. In: Greening Rooftops for Sustainable Communities. Proc. North American Green Roof Conf.Toronto: The Cardinal Group, Portland.

Bengtsson, L., 2005. Peak flows from thin sedum-moss roof. Nordic Hydrol. 36, 269280.

Benvenuti, S., 2014. Wildflower green roofs for urban landscaping, ecological sustainability and biodiversity. Landscape Urban Plann. 124, 151-161.

Berretta, C., Poë, S., Stovin, V., 2014. Moisture content behaviour in extensive green roofs during dry periods: the influence of vegetation and substrate characteristics. J. Hydrol. 511, 374-386.

Bousselot, J.M., Klett, J.E., Koski, R.D., 2011. Moisture content of extensive green roof substrate and growth response of 15 temperate plant species during dry down. HortScience 46, 518-522.

Brenneisen, S., 2006. Space for urban wildlife: designing green roofs as habitats in Switzerland. Urban Habitats 4, 10.

Brown, V.K., Gange, A.C., Evans, I.M., Storr, A.L., 1987. The effect of insect herbivory on the growth and reproduction of two annual vicia species at different stages in plant succession. J. Ecol. 75, 1173-1189.

Dunnett, N., Kingsbury, N., 2008. Planting Green Roofs and Living Walls. Timber Press, Portland.

Durhman, A.K., Rowe, D.B., Rugh, C.L., 2007. Effect of substrate depth on initial growth, coverage, and survival of 25 succulent green roof plant taxa. HortScience 42, 588-595. 
Edwards-Jones, G., Brown, V.K., 1993. Successional trends in insect herbivore population densities: a field test of a hypothesis. Oikos 66,8 .

Emilsson, T., 2008. Vegetation development on extensive vegetated green roofs: influence of substrate composition, establishment method and species mix. Ecol. Eng. 33, 265-277.

Emilsson, T., Czemiel Berndtsson, J., Mattsson, J.E., Rolf, K., 2007. Effect of using conventional and controlled release fertiliser on nutrient runoff from various vegetated roof systems. Ecol. Eng. 29, 260-271.

Emilsson, T., Rolf, K., 2004. Comparison of establishment methods for extensive green roofs in southern Sweden. Urban For. Urban Greening 3, 103-111.

Fitter, R., Fitter, A., Blamey, M., 1996. Wild Flowers of Britain and Northern Europe (Collins Pocket Guide), 5th edition Harper Collins Pub, London.

FLL, 2008. Guidelines for the Planning, Execution and Upkeep of Green-Roof Sites (English version). Forschungsgesellschaft Landschaftsentwicklung Landschaftsbau e.V., Troisdorf, Germany.

Fowler, J., Cohen, L., Jarvis, P., 1998. Practical Statistics for Field Biology, second edition John Wiley \& Sons.

Gedge, D., 2001. Roofspace - a place for brownfield biodiversity? Ecos 22, 69-74.

Gedge, G., Grant, G., Kadas, G., Dinham, C., 2012. Creating Green Roofs for Invertebrates?a Best Practice Guide. Peterborough: Buglife.

Gibson, C.W.D., 1998. Brownfield: red data. The values artificial habitats have for uncommon invertebrates. English Nature Research Report, .

Graceson, A., Hare, M., Monaghan, J., Hall, N., 2013. The water retention capabilities of growing media for green roofs. Ecol. Eng. 61, 328-334.

Grant, G., Engleback, L., Nicholson, B., 2003. Green roofs: their existing status and potential for conserving biodiversity in urban areas. English Nature Research Report No. 498, .

Hull, A.C., 1974. Seedling emergence and survival from different seasons and rates of seeding mountain rangelands. J. Range Manage. 27, 302-304.

Ishimatsu, K., Ito, K., 2013. Brown/biodiverse roofs: a conservation action for threatened brownfields to support urban biodiversity. Landscape Ecol. Eng. 9, 299-304.

Kadas, G.J., 2007. Can Green Roofs Provide Habitat for Invertebrates in an Urban Environment? Unpub. Ph.d Thesis. Royal Holloway Univ., London.

Köhler, M., Poll, P.H., 2010. Long-term performance of selected old Berlin greenroofs in comparison to younger extensive greenroofs in Berlin. Ecol. Eng. 36, 722-729.

MacIvor, J.S., Margolis, L., Puncher, C.L., Carver Matthews, B.J., 2013. Decoupling factors affecting plant diversity and cover on extensive green roofs. J. Environ. Manage. 130, 297-305.

Madre, F., Vergnes, A., Machon, N., Clergeau, P., 2013. A comparison of 3 types of green roof as habitats for arthropods. Ecol. Eng. 57, 109-117.

Madre, F., Vergnes, A., Machon, N., Clergeau, P., 2014. Green roofs as habitats for wild plant species in urban landscapes: first insights from a large-scale sampling. Landscape Urban Plann. 122, 100-107.

Mickovski, S.B., Buss, K., McKenzie, B.M., Sökmener, B., 2013. Laboratory study on the potential use of recycled inert construction waste material in the substrate mix for extensive green roofs. Ecol. Eng. 61, 706-714.

Molineux, C.J., 2010. Development of Suitable Growing Media for Effective Green Roofs. Royal Holloway University, Egham, UK.
Molineux, C.J., Connop, S.P., Gange, A.C., 2014. Manipulating soil microbial communities in extensive green roof substrates. Sci. Total Environ. 493, 632-638.

Molineux, C.J., Fentiman, C.H., Gange, A.C., 2009. Characterising alternative recycled waste materials for use as green roof growing media in the U.K. Ecol. Eng. 35, 1507-1513.

Monterusso, M.A., Bradley Rowe, D., Rugh, C.L., 2005. Establishment and persistence of Sedum spp. and native taxa for green roof applications. HortScience 40, 391-396.

Morgan, S., Celik, S., Retzlaff, W., 2013. Green roof storm-water runoff quantity and quality. J. Environ. Eng. 139, 471-478.

Nagase, A., Dunnett, N., 2010. Drought tolerance in different vegetation types for extensive green roofs: effects of watering and diversity. Landscape urban plann. 97, 318-327.

Nagase, A., Dunnett, N., 2011. The relationship between percentage of organic matter in substrate and plant growth in extensive green roofs. Landscape Urban Plann. 103, 230-236.

Nagase, A., Dunnett, N., 2013. Establishment of an annual meadow on extensive green roofs in the UK. Landscape Urban Plann. 112, 50-62.

Niemelä, J., 2014. Ecology of urban green spaces: the way forward in answering major research questions. Landscape Urban Plann. 125, 298-303.

Oberndorfer, E., Lundholm, J., Bass, B., Coffman, R., Doshi, H., Dunnett, N., Gaffin, S. Kohler, M., Liu, K., Rowe, B., 2007. Green roofs as urban ecosystems: ecological structures, functions, and services. BioScience 57, 10.

Olly, L.M., Bates, A.J., Sadler, J.P., MacKay, R., 2011. An initial experimental assessment of the influence of substrate depth on floral assemblage for extensive green roofs. Urban For. Urban Greening 10, 311-316.

Sadler, J.P., Bates, A.J., Bodnar, S., 2011. Building for Biodiversity: Accommodating People and Wildlife in Cities. Oxford University Press, Oxford, UK.

Snodgrass, E., Snodgrass, L., 2006. Green Roof Plants, A Planting and Resource Guide. Timber Press.

Southwood, T.R.E., Brown, V.K., Reader, P.M., Green, E.E., 1986. The use of different stages of secondary succession by birds. Bird Study 33, 5 .

Tonietto, R., Fant, J., Ascher, J., Ellis, K., Larkin, D., 2011. A comparison of bee communities of Chicago green roofs, parks and prairies. Landscape Urban Plann. $103,102-108$.

Vander Mijnsbrugge, K., Bischoff, A., Smith, B., 2010. A question of origin: where and how to collect seed for ecological restoration. Basic Appl. Ecol. 11, 300-311.

VanWoert, N.D., Rowe, D.B., Andresen, J.A., Rugh, C.L., Fernandez, R.T., Xiao, L., 2005 Green roof stormwater retention: effects of roof surface, slope, and media depth. J. Environ. Qual. 34, 1036-1044.

Volder, A., Dvorak, B., 2014. Event size, substrate water content and vegetation affect storm water retention efficiency of an un-irrigated extensive green roof system in Central Texas. Sustainable Cities Soc. 10, 59-64.

Wang, J., Zhao, X., Peng, S., Wang, X., 2013. Research on the runoff retention performance of a green roof for urban rainwater runoff control. J. Food Agric. Environ. 11, 2429-2432.

Zheng, M.F., Deng, Y., Liu, R.F., Mi, J.S., Luo, X.M., 2013. Influence of two greenroofs on runoff quantity and quality. Zhejiang Daxue Xuebao (Gongxue Ban) [J. Zhejiang Univ. (Eng. Sci.)] 47, 1846-1851. 